\title{
Expelling stones with ultrasonic propulsion
}

Ultrasonic propulsion can be used to reposition kidney stones and facilitate the passage of stone fragments, according to a new study.

Ultrasonic propulsion technology was previously demonstrated to be safe and effective in a porcine model, but this study is the first trial of this technology in humans.

Fifteen patients were included in the study and underwent screening ultrasonography, with which 43 stone targets were identified. The stonepushing procedure was performed by a sonographer and a urologist: two patients underwent the procedure while anaesthetized for simultaneous ureteroscopy, and 13 patients underwent the procedure while awake and without sedation. Patients completed a pain questionnaire before and after the procedure, were contactly weekly for 3 weeks, and their medical charts were reviewed for 90 days to assess for adverse events and stone passage.

Harper et al. report that stones were repositioned in 14 of the 15 patients. Overall, 28 of the 43 targets were moved to some degree and 13 were displaced by $>3 \mathrm{~mm}$ to a new location. Displacement of $>3 \mathrm{~mm}$ was achieved with postlithotripsy fragments and small de novo stones that were known to be loose. Stones $>5 \mathrm{~mm}$ were able to be moved slightly, but not displaced to a new location. Among four of six patients who had previously undergone lithotripsy, more than 30 stone fragments were passed within days following the procedure.
No serious or device-related adverse events were reported and discomfort during the procedure was rare and reported as being mild and brief.

The authors also report that in at least four patients, what seemed to be a single large stone on imaging was actually a cluster of smaller passable stones. "This is particularly important," say the authors, "as stone size is a major factor in management of urolithiasis. Most stones $<5 \mathrm{~mm}$ will pass spontaneously, while stones $\geq 5 \mathrm{~mm}$ often require intervention."

Rebecca Kelsey

ORIGINAL ARTICLE Harper, J. D. First-in-human clinical trial of ultrasonic propulsion of kidney stones. J.Urol. http://dx.doi.org/10.1016/j.juro.2015.10.131 